\title{
Human Capital Investments in Pakistan: Implications of Micro Evidence from Rural Households
}

\begin{abstract}
YASUYUKI SAWADA
A number of cross-country studies suggest that the Pakistani aggregate human capital investments, measured by educational performance, are low relative to other countries of similar per capita income levels. This paper investigates the implications of micro evidence on schooling from rural Pakistan for an understanding of the cases of low human capital investments. The results of school-entrant and dropout regressions using household panel data indicate that the permanent and transitory income movements affect children's schooling behaviour, indicating credit market imperfections. Hence, the human capital investments in rural Pakistan may be discouraged by poverty, combined with incompletely insured income volatility. Moreover, our analysis points out that there is a distinct gender difference in education.
\end{abstract}

\section{INTRODUCTION}

A number of cross-country studies suggest that the aggregate human capital investments in Pakistan are low relative to other countries of similar per capita income levels [Behrman and Schneider (1993); Birdsall, Ross and Sabot (1993) and Summers (1992)]. Figure 1 portrays the relationship across 108 countries in 1985 between per capita real GDP and the percentage of primary school attained in the total population. In Figure 1, Pakistan is well below the cross-country regression line. This implies that the Pakistani human capital investments have been relatively low, controlling for differences in the per capita income level. The problem of high dropout rate in schooling seems to be serious in Pakistan as well. Figure 2 represents the cross-country relationship between the income level and the dropout rate. Although we can see that there is a cross-country negative relationship between

Yasuyuki Sawada is a Ph.D. candidate in the Department of Economics, Stanford University, USA.

Author's Note: This research was financially supported by the Matsushita International Foundation. I would like to thank Richard Adams, Harold Alderman, Abid A. Burki, Mohammad Emran, Marcel Fafchamps, Lawrence Haddad, Haroona Jatoi, Keijiro Otsuka, Agnes Quisumbing, and Julie Schaffner for useful comments.

Keywords: Gender Gap and Education in Pakistan; Risk-coping Strategies; Fixed Effects Logit Model. 


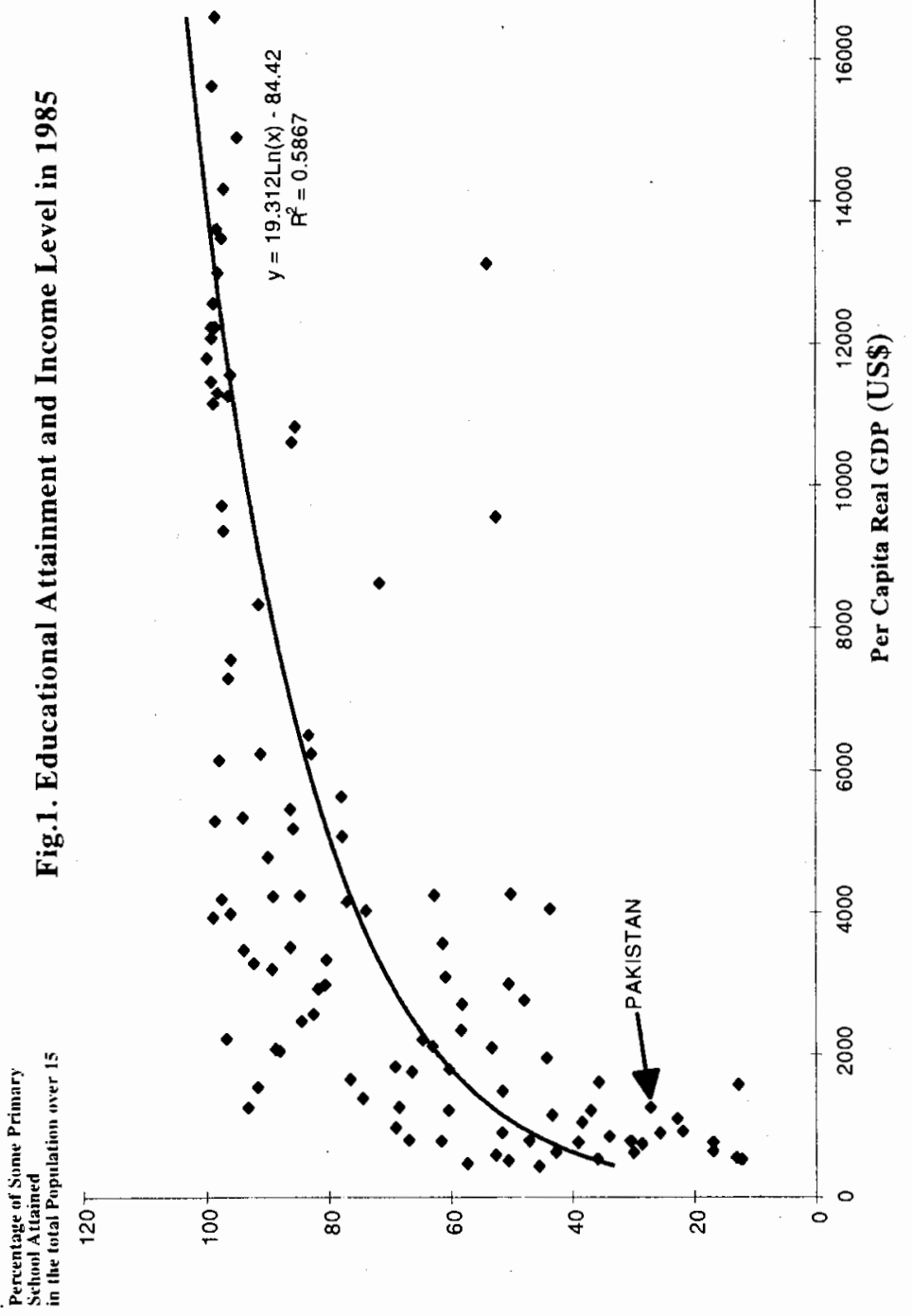

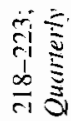

$\dot{\infty} \infty$

怘

政

so

87

苛畩

急全

莺衣

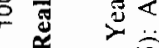

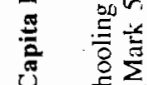

¿

ㄴ.

를 옹

获

J

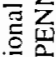

苞

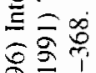

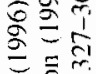

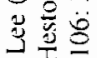

$3<$

可壱

西

¿

总㤩

छ 


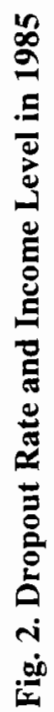

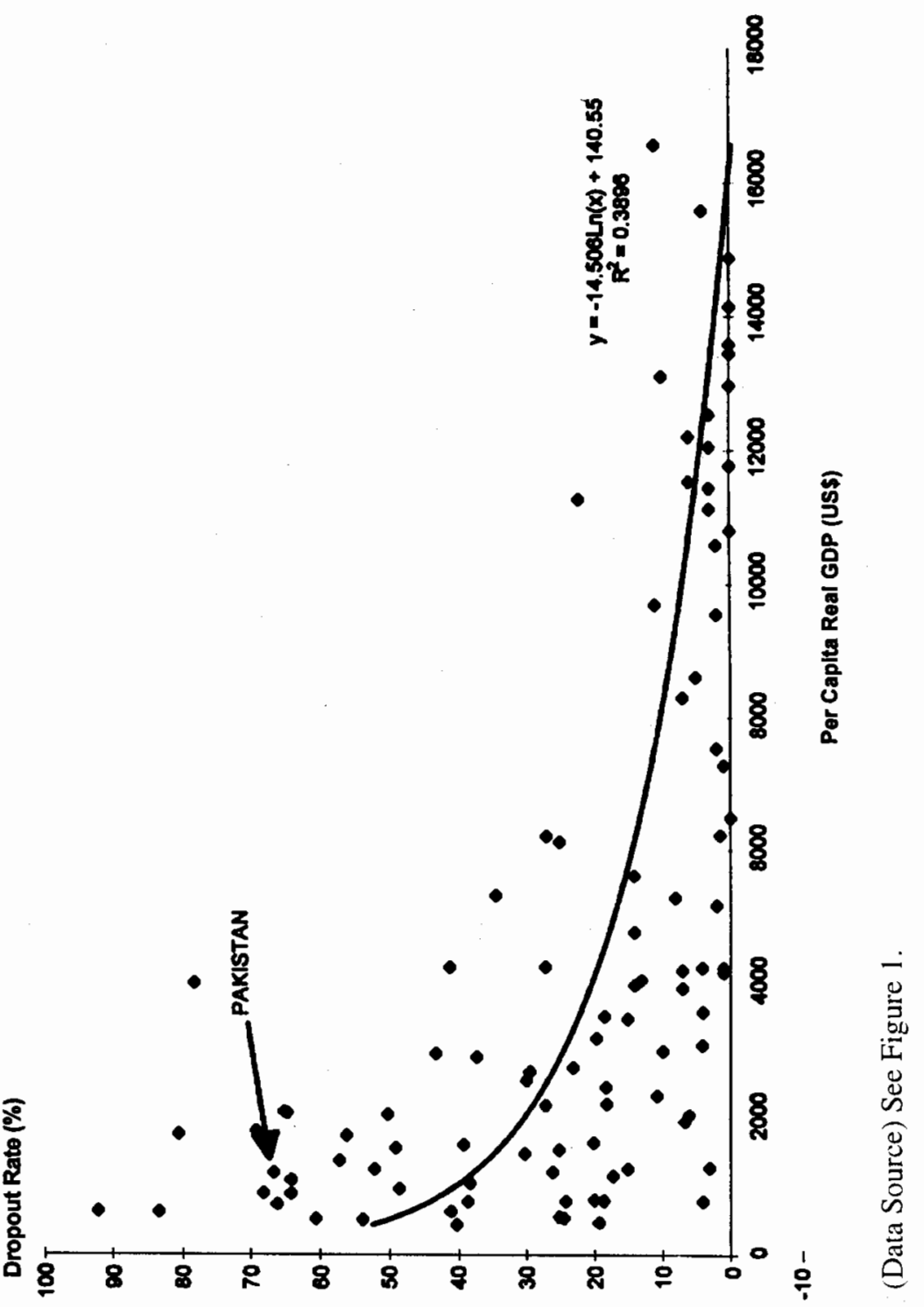


these two variables, Pakistan is well above the fitted line, indicating that Pakistan has had relatively high dropout rate in an international perspective. Moreover, the investments have been biased towards males relative to females. Figure 3 depicts the relationship between the per capita real GDP and a gender gap measure. Pakistan is well above the cross-country regression line. This observation indicates that Pakistani parents favour sons in terms of education.

What are the implications of these observations for economic development of Pakistan? The results of recent cross-country growth regressions show that, once the starting level of real per capita GDP is held constant, the school-attainment variables are significantly related to the growth rate of real per capita GDP [Barro and Sala-iMartin (1995)]. Therefore, economic growth in Pakistan may be seriously affected by the low levels of investment in human capital, particularly by the low level of women's education. Birdsall, Ross and Sabot's (1993) regression results indicate substantial forgone income gains for Pakistan due to low investments in schooling over the last three decades. Their simulations revealed that Pakistan would have increased the current per capita income by 25 percent if it had had Indonesia's 1960 primary school enrollment rates, and by 16 percent if as many girls as boys had attended primary school in 1960.

In these cross-country studies, however, the micro-level mechanisms of human capital investments are not necessarily clear. To answer the questions about the tools and timing of an appropriate education policy, we need to capture microlevel household behaviour. Risk, uncertainty, and constraints on access to credit all potentially influence the production and consumption decisions of poor farmers in the developing countries. ${ }^{1}$ In particular, the market forces usually fail to provide both credit and insurance to investments in human capital. Hence, it is only natural to regard the human capital investments in rural Pakistan as intertemporal optimising decisions made by the farm households under conditions of credit and insurance market incompleteness. Since the poor households, especially the landless farmers, frequently can not borrow against their future income, they are likely to have high marginal utility of current consumption. ${ }^{2}$ Therefore, the opportunity cost of child education is quite high, and thus transitory shocks to parental income may lead to a decline in school attendance. This is the hypothesis of child labour as income insurance proposed by Jacoby and Skoufias (1997). Their empirical results indicate that, in southern Indian villages, seasonal fluctuations in school attendance are a form of self-insurance for households vulnerable to risk.

${ }^{1} \mathrm{~A}$ number of recent microeconomic studies address the role of formal and informal risk mitigating mechanisms of LDC farm households [Alderman and Paxson (1992); Fafchamps (1992); Morduch (1994) and Townsend (1995)].

${ }^{2}$ The credit constraints on households are driven by credit market imperfections, which may result from financial repression such as interest rate restrictions imposed by government or from asymmetric information between lenders and borrowers. 


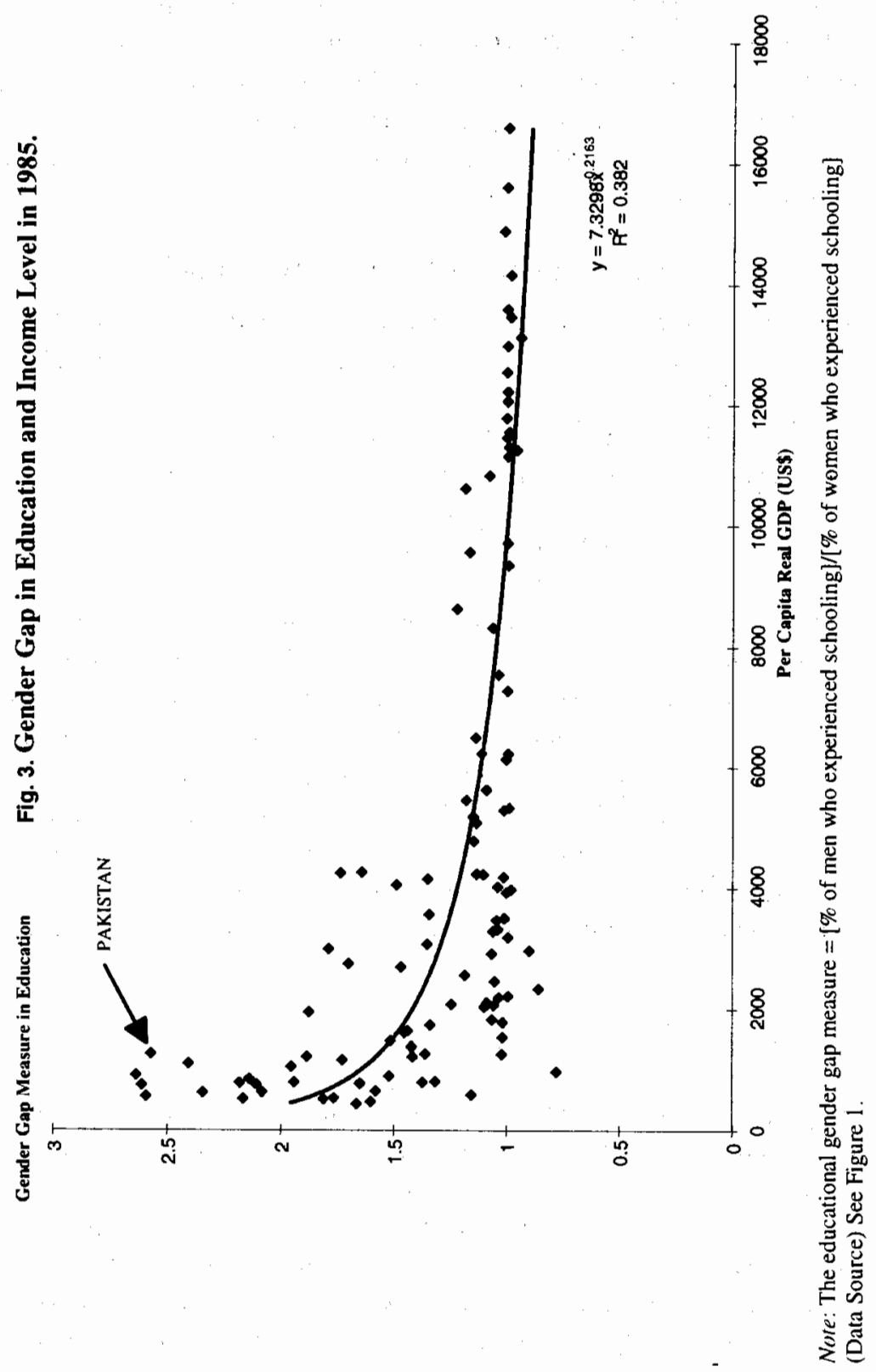


Using a panel data set, this paper tests whether credit market imperfections are serious obstacles to human capital investments in rural Pakistan. Unlike the Jacoby and Skoufias (1997) paper, we consider the difference between the school entry and dropout decisions explicitly, and take into account the gender gap in education, which seems to be a very important issue in Pakistan. Section II summarises the conceptual framework. Section III presents an empirical model to investigate the theoretical implications and the data set used in this paper. The final section includes estimation results and conclusions.

\section{THE THEORETICAL FRAMEWORK ${ }^{3}$}

The return to the human capital of a child, measured by wage availability $W$, is assumed to be a function of years of schooling $S$, child specific factors $\mathrm{CH}$, gender specific indicator variable $F E M$ ( $=1$ if the child is female and $=0$ if male), village specific school quality $V$, and an additive stochastic element $e$ which incorporates possibilities such as risk of job-mismatching after schooling with $E(e)=0$ :

$W(S)=f(S, C H, F E M, V)+e, f_{S}>0, f_{S S}<0 . \ldots \quad \ldots \quad \ldots$

This human capital production function is assumed to be concave in years of schooling so that the return to increments in schooling falls gradually. Moreover, the hypothesis of gender gap in wage level or return to education will be that $f(S$, $C H, 0, V)>f(S, C H, 1, V)$. When a household can borrow and save money freely at an exogenous interest rate with a normalisation, $W(0)=1$, we have the following first-order condition: $\chi(S ; C H, F E M, V) / \partial S=1+r$. This equation indicates that a household with perfect access to credit will determine the level of schooling so as to equalise the net marginal productivity of schooling and the non-stochastic market interest rate. Hence, the optimal schooling decision rule is a simple reduced form equation:

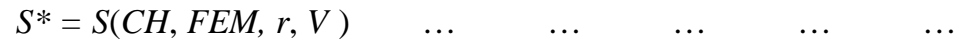

This Equation (2) indicates that when credit constraint is not binding, the separability between consumption and schooling investment decisions holds, and parental income does not affect the schooling decision.

However, the households in developing countries, especially poor landless farm households, are likely to be credit-constrained. Under a binding credit constraint, households might adjust child schooling to cope with income risks. To see this mechanism formally, we can derive a credit-constrained household's optimal

${ }^{3}$ The technical appendix is available upon request. Sawada (1997) also provides a full solution of the model in this section. 
schooling decision equation in a two-period framework: $\partial f(S, C H, F E M, V) / \partial S=$ $\left(\partial E U / \partial C_{1}\right) /\left(\partial E U / \partial C_{2}\right)$, where $E U$ denotes the expected lifetime utility of the household. Under credit market imperfections, the household effectively faces an endogenous interest rate as we can see in the right hand side. This indicates that the separability between consumption and schooling investment decisions breaks down. ${ }^{4}$ Under this non-separability, the reduced form schooling decision becomes:

$$
S^{*}=S\left(Y_{P}, Y_{T}, C H, F E M, r, V\right), \quad \ldots \quad \ldots \quad \ldots \quad \ldots
$$

where $Y_{P}$ and $Y_{T}$ represent permanent and transitory income of parents, respectively.

\section{THE ECONOMETRIC FRAMEWORK AND DATA SET}

\section{A Two-step Procedure}

The existence of credit market imperfections can be investigated by testing whether coefficients of $\left(Y_{P}, Y_{T}\right)$ are zero or not [see Equations (2) and (3)]. Another aim of our empirical analysis is to test whether there is a distinct gender gap in education by inspecting the relationship, $f(S, C H, 0, V)>f(S, C H, 1, V)$. However, the optimal years of schooling is not observable if children do not attend schools or if fail to graduate. Hence, we need to employ a model which can take into account the potential bias due to truncated distributions. Our approach here is to construct a model of binary dependent variables and to estimate equations for dropouts from school separately from entrants to school by a two step procedure.

In the first stage, we will decompose income into permanent and transitory components, using a definition, $Y_{t}=Y^{P}+Y_{t}^{T}$, where $E\left(Y^{T}\right)=0$. The first method to estimate permanent and transitory components from actual data is to calculate simple mean and deviation of household income over time, i.e., $Y^{P}=\frac{1}{T} \sum_{t=1}^{T} Y_{t}, Y_{t}^{T}=Y_{t}-Y^{P}$. The second approach to the decomposition of income is somewhat similar to the first method. We assume that consumption can be decomposed into permanent income and mean-zero transitory income components: $C_{t}=Y^{P}+Y_{t}^{T}{ }^{5}$ Permanent income $Y^{P}$ is calculated as the average consumption over time, and transitory income $Y^{T}$ is calculated as the deviation of consumption from its sample mean.

Conceptually, sampled children can be classified in one of the following categories: (i) no schooling, (ii) entrant, (iii) continuing schooling and (iv) dropout. These are mutually exclusive and exhaustive categories. ${ }^{6}$

${ }^{4}$ Using a micro data set from five villages in the Pakistan Punjab, Kurosaki and Fafchamps (1997) show that the separability between production and consumption decisions breaks down.

${ }^{5}$ Note that we take into consideration possible deviations from perfect credit and insurance markets by adding transitory components.

${ }^{6}$ We simply assume that the history of schooling decisions is pre-determined and exogenously given since data on the entire history of past schooling choices is not available. 


\section{The Framework for Entrants}

For the sample that is composed of (i) no schooling and (ii) school entrants, we can define a binary variable, ENT. For children before schooling, ENT $=0$ and for those children who enter school, ENT $=1$ at the entrance year. Utilising linear approximations to Equation (3), we can construct a discrete dependent model as follows:

$$
\begin{aligned}
& E N T_{i t}=0 \text { if } S_{i t}^{*}=X_{i t} \pi+\varepsilon_{i t} \leq 0, \\
& E N T_{i t}=1 \text { if } S_{i t}^{*}=X_{i t} \pi+\varepsilon_{i t}>0,
\end{aligned}
$$

where $\varepsilon$ is a measurement error, and $X$ is a matrix which is defined as $X \equiv\left[Y^{P}, Y^{T}\right.$, $\mathrm{CH}, \mathrm{FEM}, \mathrm{V}]$. We estimate this qualitative response model with fixed effects to control for village specific characteristics.

It is difficult, in general, to justify the choice of one distribution or another on theoretical grounds [Amemiya (1981)]. It has been found, however, that maximisation of the fixed effects likelihood function can give seriously inconsistent estimators if there are only a small number of observations per group. Chamberlain (1980) developed a conditional likelihood function approach which could be applied directly to the fixed effect logit probability model to obtain the consistent estimates of the coefficients and standard error. Hence, we will implement the estimation of the model assuming that the cumulative distribution function, $F(\varepsilon)$, is logistically distributed.

Recalling Equations (2) and (3), our hypothesis of the perfect credit market will be: $H_{0}: \pi^{P}=0$ and $\pi^{T}=0$ and $H_{A}: \pi^{P} \neq 0$ and $\pi^{T} \neq 0$, where $\pi^{P}$ and $\pi^{T}$ represent coefficients on permanent and transitory incomes respectively. If the null hypothesis cannot be rejected, we can conclude that credit constraint is not binding. Rejecting the null implies that credit market imperfections play a role in schooling decisions.

\section{The Framework for Dropouts}

In the regression for dropouts, we use the sample of (iii) continuing and (iv) dropout students. We define an unobserved variable, $R E M$, as the remaining years of education of children, $R E M_{i t}=S_{i t}^{*}-D U R_{i t}$, where $D U R$ is defined as the child $i$ 's total years of education prior to time $t$. Suppose that $R E M$ can be approximated by a linear function of $X$ with a measurement error with mean zero and finite variance. Then, our estimation model becomes:

$$
\begin{aligned}
& D R P_{i t}=0 \text { if } R E M_{i t}=X_{i t} \beta+u_{i t}>0 \\
& D R P_{i t}=1 \text { if } R E M_{i t}=X_{i t} \beta+u_{i t} \leq 0
\end{aligned}
$$


where $u$ is a measurement error, $X$ is a matrix which is defined as $X \equiv\left[Y^{P}, Y^{T}, C H\right.$, $F E M, V]$. The binary dependent variable $D R P$ represents schooling continuation (if $D R P=0$ ) or dropout (if $D R P=1$ ). We will estimate the model of (5) by maximising the conditional likelihood function with the assumption of logistic distribution as before. Our null hypothesis of the perfect credit market will be: $H_{0}: \beta^{P}=0$ and $\beta^{T}=$ 0 and $\mathrm{H}_{\mathrm{A}}: \beta^{P} \neq 0$ and $\beta^{T} \neq 0$, where $\beta^{P}$ and $\beta^{T}$ represent coefficients on permanent and transitory incomes respectively.

\section{The Data Set}

We employ a panel data from Pakistani villages collected through the International Food Policy Research Institute (IFPRI) Pakistan Food Security Management Project [Alderman and Garcia (1993)]. ${ }^{7}$ The IFPRI panel data set was collected by 14 rounds of survey (rd 1-14) over five years from July 1986 (Kharif season) to September 1991 (Rabi season). Around one thousand randomly selected households from 44 villages are included in the initial survey. The IFPRI household surveys were conducted in the least developed districts in the three Pakistan provinces, i.e., Punjab (Attock), Sindh (Badin) and North-West Frontier Province (Dir) provinces. A well-developed and irrigated district, Faisalabad district in Punjab province, was also included in the survey for comparison purposes.

For income decomposition, we utilise the five-year panel data of 764 households from 1986-87 until 1990-91. For the logit estimations, however, due to the unavailability of schooling data in the later years, we employ three year panel data for children of ages between two and nineteen years for entrants and between five and nineteen years for dropouts, together with household background data. The child specific characteristics are assumed to be captured by sibling composition dummies, relation-to-household-head dummies, and age specific dummies. The effects of the gender specific parameters are captured simply by a gender dummy variable. ${ }^{8}$ Time specific effects, $t_{t}$, are also added to control for effects of aggregate shocks. The village specific effects are incorporated in the logit model to control for unobserved village characteristics including local difference in school supply and in degree of financial development.

\section{EMPIRICAL RESULTS AND CONCLUDING REMARKS}

\section{Empirical Results of Entrant Regressions}

The results of entrant regressions for children of age 2-19 years are reported

${ }^{7}$ Studies using the IFPRI Pakistan panel data set include Alderman (1996), Fafchamps and Quisuimbing (1997), and Gillani (1996).

${ }^{8}$ Interestingly, 75 percent of children in the entrant regression is female and 77 percent of children in the dropout regression is male. These numbers indicate that many girls have been uneducated and the percentage of boys at schools are significantly higher than that of girls. 
in Table 1. First, coefficients in the income blocks are consistently positive, implying that higher permanent income and a positive shock to income enhance the probability of entrance to school. The joint Wald tests of the null hypothesis of no permanent and transitory income effects are rejected statistically in both specifications. Recalling Equations (2) and (3), our empirical results indicate the existence of imperfect credit markets in these Pakistani villages.

Second, in the child characteristics blocks, all of the gender dummy coefficients (FEM) are negative and significant, indicating that daughters have consistently lower probability of entrance to school than that of sons. Third, we can calculate the odds ratios from the results of age specific effects (Figure 4). These results suggest that children have the highest relative probability of entering school at age of six. There is another peak at the age of twelve. This second peak seems to correspond to the year of middle school entrance, which represent delays of school entry and/or grade repetitions in these villages.

\section{Empirical Results of Dropout Regressions}

Preliminary findings of dropout regressions can be summarised as follows (Table 1). First, coefficients in the income blocks are consistently negative, which implies that higher permanent income as well as positive transitory income reduce the probability of dropping out from school. These results imply that these households in rural Pakistan face binding credit constraints, recalling Equations (2) and (3). Second, all of the female dummy coefficients (FEM) are positive and significant, indicating that girls have higher probabilities of dropping out of school than boys do. After having entered a school, a daughter will obtain systematically less education than a son. Third, in the sibling blocks, all of the eldest male and female sibling dummy coefficients are negative and statistically significant, indicating that the eldest brother has the lowest probability of dropping out from school. This might imply that there is a particular preference for eldest son's education.

\section{Concluding Remarks}

Results of entrant and dropout regressions imply that households in these Pakistani villages might be credit constrained. Transitory poverty as well as absolute poverty are serious obstacles to human capital accumulation in rural Pakistan.

The opportunity costs of female education might be quite high especially in the rural Pakistan setting; daughters can accomplish various household tasks such as child-care, housekeeping, and meal preparations [Shah (1986)]. Nevertheless, investment in the education of daughters may not yield much economic returns for parents. First, a daughter moves to the other family after marriage, and thus returns 


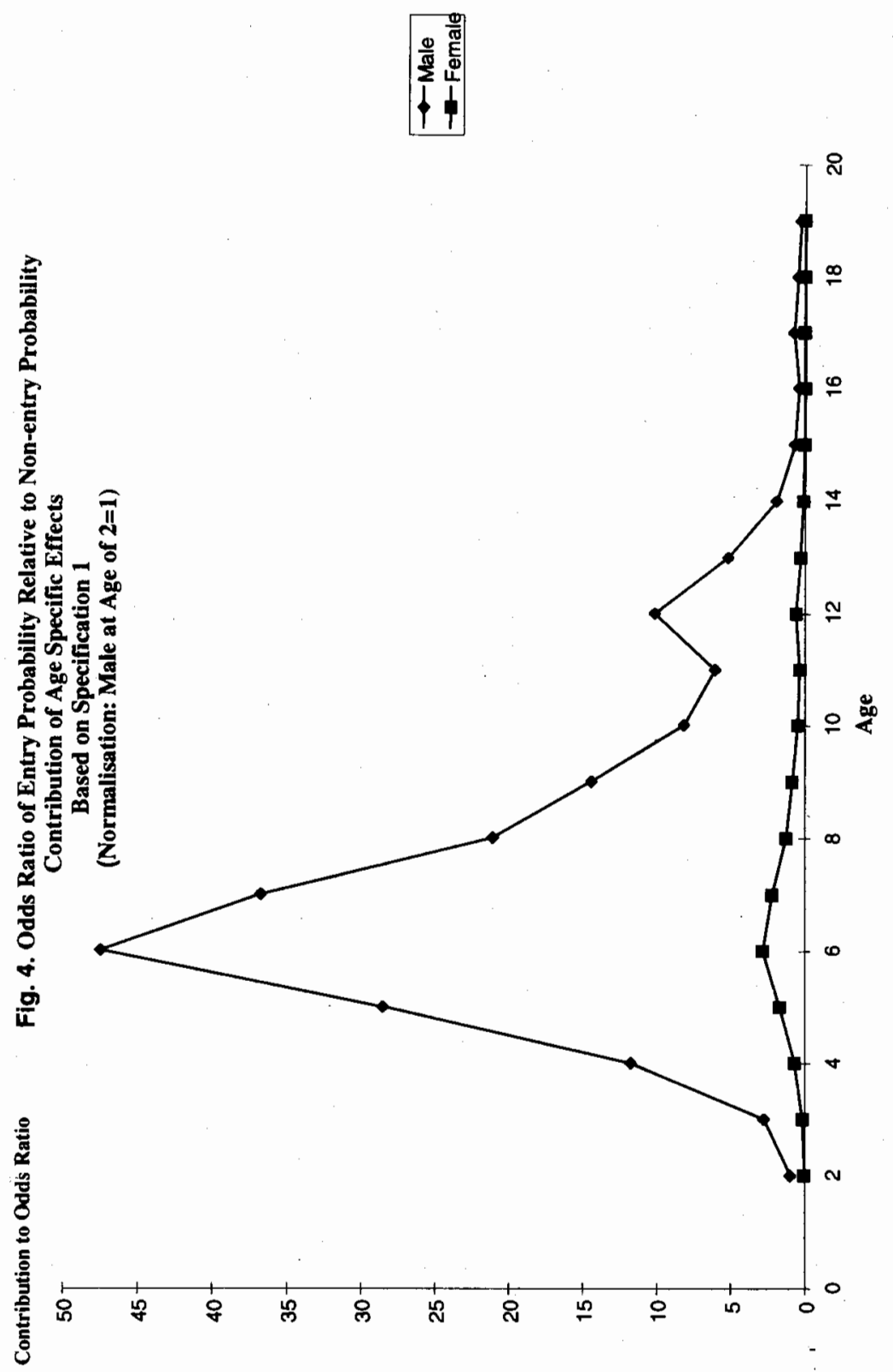




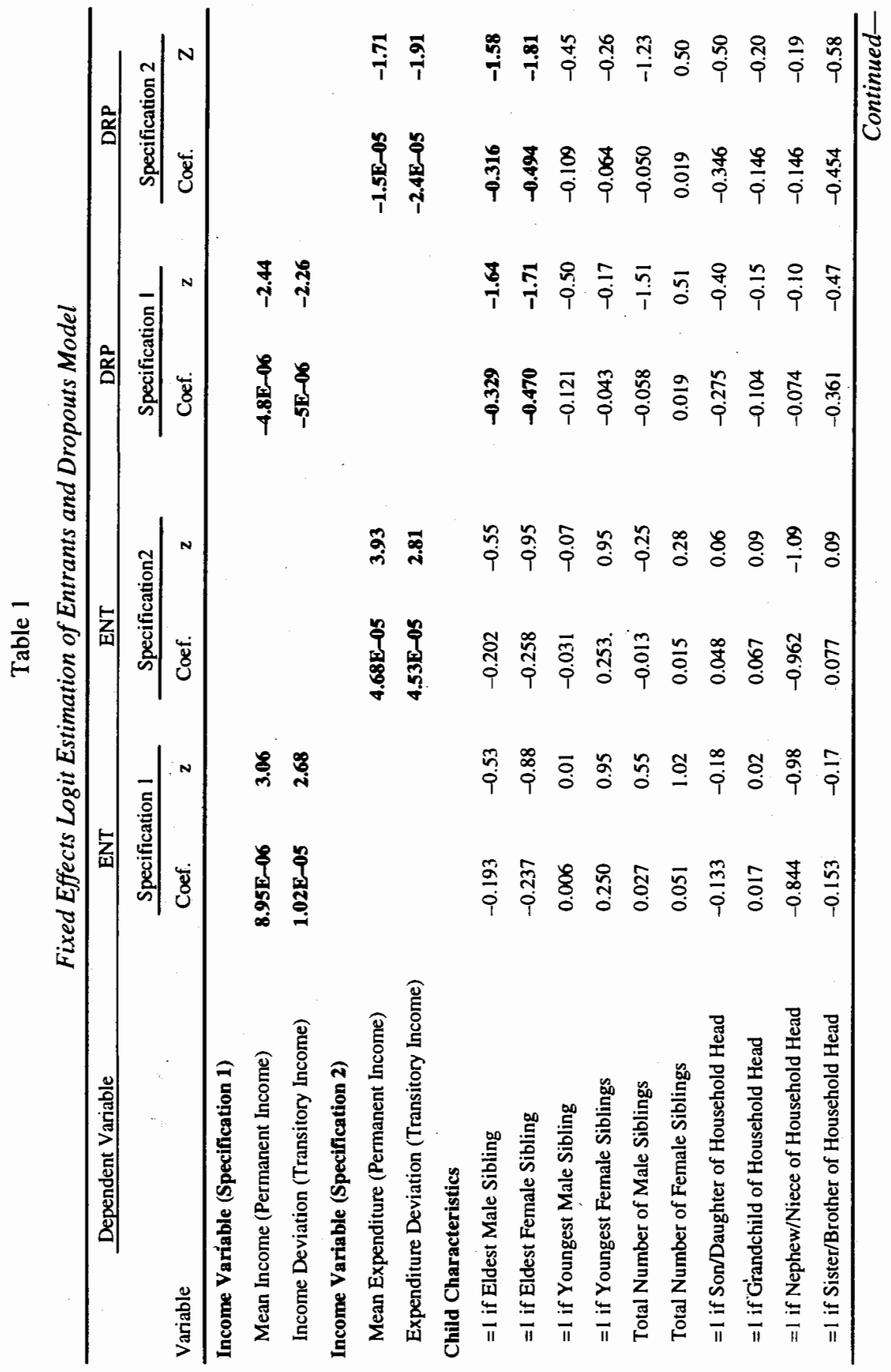




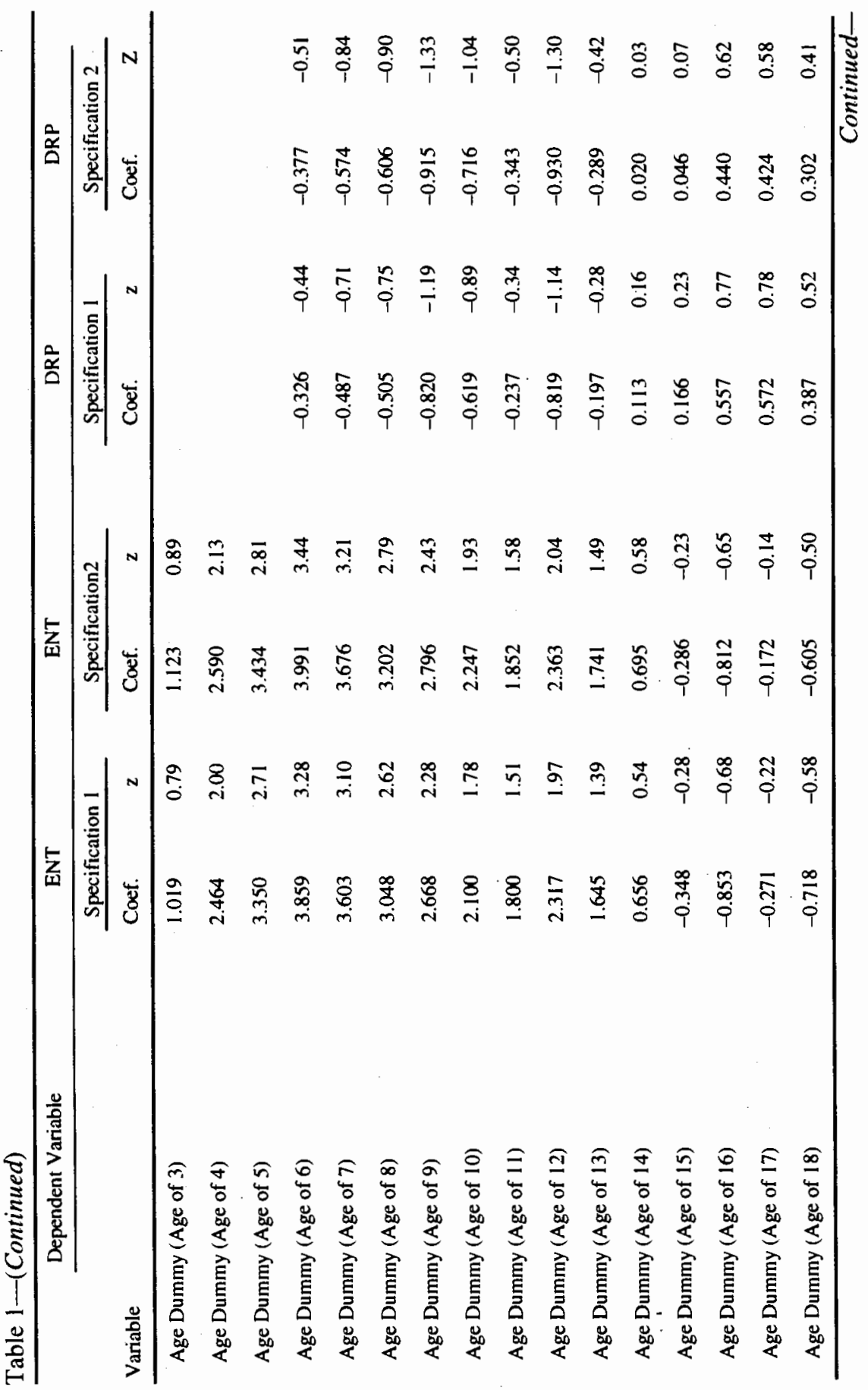




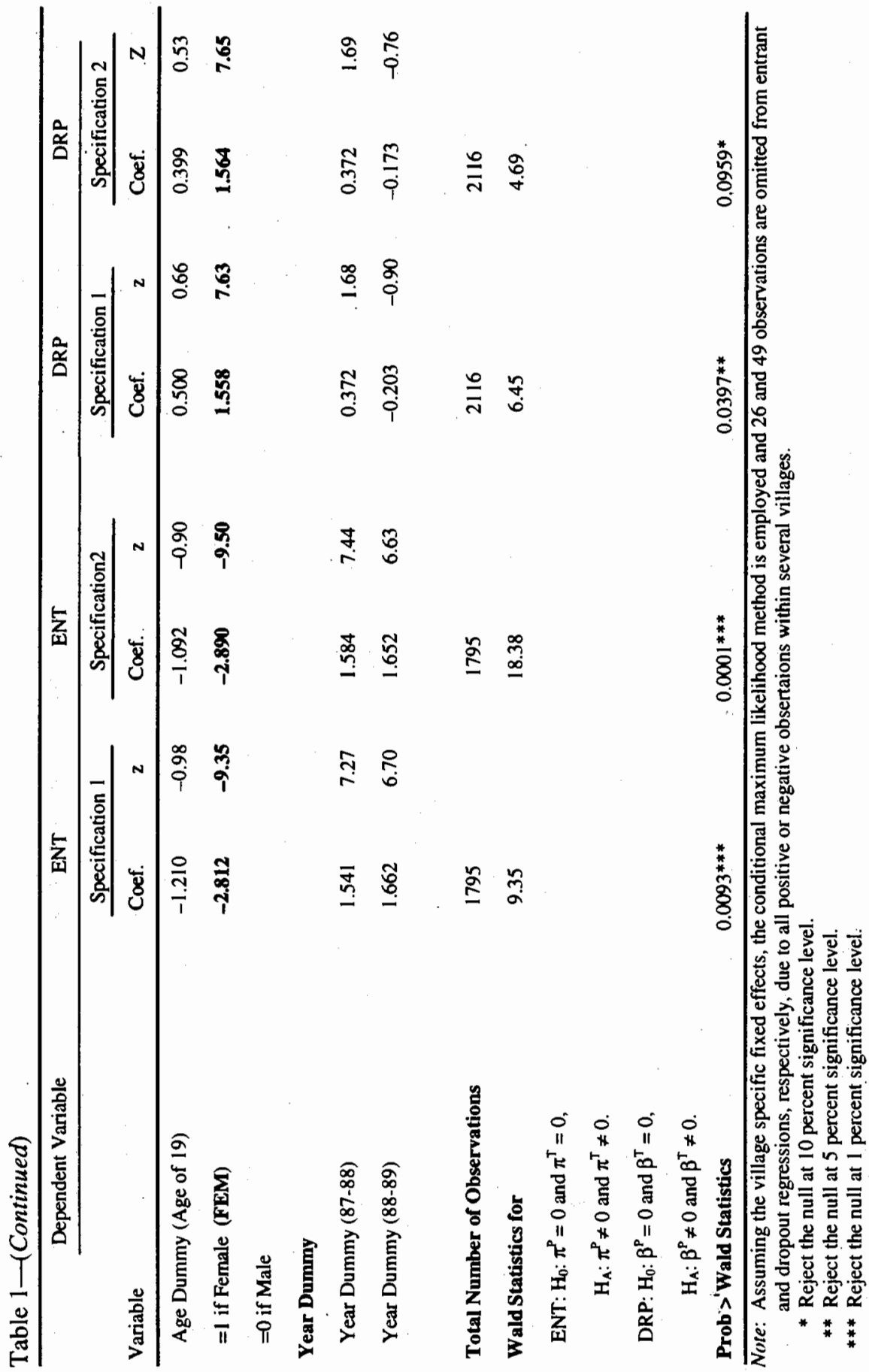


from daughter's education "leak" to the other family. Second, because of the practice of purdah, relatively limited wage earning opportunities are available to women. Hence, there are less economic incentives for human capital investments in daughters. Our estimation results of the relatively poor educational attainments of daughters indicate that parents apparently prefer to educate sons, particularly the eldest.

These results imply that the schooling of children is significantly related to a household's risk-coping behaviour under credit market imperfections. The poor households might even employ perverse strategies to buffer consumption against income shocks, sacrificing in return the education of their daughters. According to our observations, various policies which alleviate transitory poverty, such as state contingent subsidies and micro-credit policies, will enhance human capital accumulation in rural Pakistan.

\section{REFERENCES}

Alderman, Harold (1996) Saving and Economic Shocks in Rural Pakistan. Journal of Development Economics 51: 343-365.

Alderman, Harold, and Marito Garcia (1993) Poverty, Household Food Security, and Nutrition in Rural Pakistan. (IFPRI Research Report 96.)

Alderman, H., and C. Paxson (1992) Do the Poor Insure? A Synthesis of the Literature on Risk and Consumption in Developing Countries. World Bank, Washington, D. C. (Policy Research Working Paper No.1008.)

Amemiya, Takeshi (1981) Qualitative Response Models: A Survey. Journal of Economic Literature 19: 481-536.

Barro, R. J., and X. Sala-i-Martin (1995) Economic Growth. McGraw Hill.

Behrman, J., and R. Schneider (1993) An International Perspective on Pakistani Human Capital Investments in the Last Quarter Century. The Pakistan Development Review 32:1 1-68.

Birdsall, Nancy, David Ross, and Richard Sabot (1993) Underinvestment in Education: How Much Growth has Pakistan Foregone? The Pakistan Development Review 32:4 453-499.

Chamberlain, G. (1980) Analysis of Covariance with Qualitative Data. Review of Economics Studies 47: 225-238

Fafchamps, Marcel (1992) Solidarity Networks in Preindustrial Societies: Rational Peasants with a Moral Economy. Economic Development and Cultural Change 41: 147-174.

Fafchamps, Marcel, and Agnes R. Quisumbing (1997) Human Capital, Productivity, and Labor Allocation in Rural Pakistan. Department of Economics, Stanford University. (Working Paper 97-019.) 
Gillani, Syeda Fizza (1996) Risk-sharing in Rural Pakistan. The Pakistan Development Review 35:1 23-48.

Jacoby, H., and E. Skoufias (1997) Risk, Financial Markets and Human Capital in a Developing Country. Review of Economic Studies 64: 311-335.

Kurosaki, Takashi, and Marcel Fafchamps (1997) Insurance Market Efficiency and Crop Choice in Pakistan. Department of Economics, Stanford University. (Working Paper 97-010.)

Morduch, J. (1994) Poverty and Vulnerability. AEA Papers and Proceedings 84 221-225.

Sawada, Y. (1997) Income Risks, Gender and Human Capital Investment in Rural Pakistan. Department of Economics, Stanford University. (Mimeographed.)

Shah, Nasra M. (1986) Pakistani Women: A Socioeconomic and Demographic Profile. Pakistan Institute of Development Economics and East-West Center.

Summers, L. (1992) Investing in All the People. The Pakistan Development Review 31:4 367-404.

Townsend, R. M. (1995) Consumption Insurance: An Evaluation of Risk-Bearing Systems in Low-Income Economies. Journal of Economic Perspectives 9: 83102. 


\section{Comments}

In this paper, the author proposes a framework to test the sensitivity of schooling to changes in permanent income $\left(Y^{P}\right)$ and transitory income $\left(Y^{T}\right)$ components of household income in Pakistan. He uses panel data from rural Pakistan and estimates fixed effects logit model on equations for dropouts from and entrants to schools. The author finds that schooling in rural Pakistan is highly sensitive to change in $Y^{P}$ and $Y^{T}$. Moreover, the author argues that households in Pakistan face binding credit constraint due to which they are unable to undertake human capital investments.

In a two-period inter-temporal environment, the author assumes that a fall in $Y^{T}$ will motivate households to switch resources from period 2 to period 1 , because marginal utility of consumption in period 1 will be higher. On this assumption, the author claims that in bad financial years for rural households, parents will use child income as an "insurance device or a risk-coping mechanism to smooth consumption.” In other words, $\frac{\partial S^{*}}{\partial Y^{T}}>0$. If this key assumption of the paper is valid, then, more or less, the author's findings are also valid. Therefore, I shall focus my comments mainly on this aspect of the paper.

In Friedman's permanent income hypothesis, the individual's consumption in a given period is determined by his/her permanent income, $Y^{P}$, that is income over his entire lifetime. A loss in income only decreases transitory income or $Y^{T}$. As a result, the permanent income of the household is decreased by only a fraction, $\frac{Z}{T}$. If individual's horizon is fairly large, it is reasonable to assume that the impact of loss in current income will be fairly small. In other words, a temporary cut in household income should have little impact on consumption.

The author rightly claims that landless rural households in Pakistan are liquidity-constrained because they cannot easily borrow due to imperfect credit markets. Therefore, the opportunity cost of child education is high for them. If the households are unable to borrow, they have no choice but to have low consumption at times when resources are low.

The paper seems to have overlooked some important facts about the behaviour of rural households in Pakistan. For example, it is fair to assume that rural households, which have a binding liquidity constraint, tend to save relatively more by consuming less. Deaton (1991) noted this aspect by the buffer-stock saving behaviour of households and argued that they have a small amount of saving which 
they use in emergency. Besides, the informal credit market in Pakistan is another important source of funding, especially for poor households, by which they can borrow to smooth their consumption. Had the author taken these aspects into account in his modelling of the consumer's utility maximisation behaviour, the implications for his results could have been different. More specifically, if the buffer-stock saving behaviour and the role of informal credit market is taken into account as control variables in the fixed effect model, the author could have obtained some other interesting results.

At another level, the author finds that "the eldest brother or sister has the lowest probability of dropping out from school.” This result seems to me quite inconsistent with his other assumptions. As claimed by the author, if parents do need to use child income as "a risk-coping mechanism to smooth consumption", then I feel that the eldest child should be more useful in supplementing household's income and, thus, should have a higher rather than a lower probability of dropping out of school.

Quaid-i-Azam University,

Abid A. Burki

Islamabad.

\section{REFERENCE}

Deaton, Angus (1991) Saving and Liquidity Constraints. Econometrica 59: (September) 1221-1248. 